\title{
EL TENDERO TRADICIONAL COLOMBIANO, UN ESTRATEGA AL NATURAL
}

\author{
Dagoberto Páramo Morales*
}

\begin{abstract}
Páramo-Morales $D$.
El tendero tradicional colombiano, un estratega al natural. Hitos de Ciencias Económico Administrativas 2012;18 (52):103-118.
\end{abstract}

\section{RESUMEN}

Objetivo: Como resultado de diferentes trabajos de investigación de corte cualitativo en busca de encontrar el papel que juega la tienda tradicional colombiana en la vida nacional, en este documento se presentan los principales argumentos que dan sentido al carácter estratégico del tendero en su natural estado de autoextensión de su propia personalidad.

Material y método: Los hallazgos se sustentan en la rigurosidad propia de los métodos etnográficos para la recopilación de la información, en las herramientas analíticas de la etnología para contrastar las diferentes realidades, y en los creativos ejercicios de interpretación que proporciona la antropología con todo su arsenal epistemológico.

Resultados: A manera de síntesis de largos años de investigación en el contexto colombiano, se señala aquí la naturaleza de las relaciones que el tendero establece con compradores -ocasionales o permanentes- con proveedores y con empleados y familiares dependientes, sobre las cuales toma sus grandes decisiones de carácter estratégico.

Conclusiones: Se sintetizan los tipos de tenderos que hasta el momento han sido descubiertos, así como una tipología de tiendas que vistas desde la perspectiva del consumidor denotan la estrategia del tendero para desarrollar su labor.
Páramo-Morales $D$.

The traditional colombian shopkeeper, a natural strategist. Hitos de Ciencias Económico Administrativas 2012;18 (52):103-118.

\section{ABSTRACT}

Objective: As a result of different qualitative researches done in order to search the role of the traditional Colombian store in the national life, here are presented the main arguments that give sense to the strategic nature of the shopkeeper in his native state of selfextension of his own personality.

Material and method: The findings are based on the strictness involved in the ethnographic methods for gathering information, on the analytical tools of ethnology to contrast the different realities, and on the creative interpretation exercises provided by the anthropology with its entire epistemological arsenal.

Results: As a synthesis of years of research in the Colombian context, it is noted here the nature of the relationships made by the shopkeeper with occasional and permanent buyers, with suppliers, and with employees and dependent relatives, on which the shopkeeper makes his great strategic decisions.

Conclusions: the types of shopkeepers that have so far been discovered are synthesized, as well as a typology of stores that from a consumer perspective denotes the shopkeeper strategy to develop his work.
Palabras clave: Tienda de barrio. Tendero. Etnografía. Etnología. Antropología. Tipos de tenderos. Tipos de tiendas. Mercadeo a la colombiana.
Key words: Neighborhood store. Shopkeeper. Ethnography. Ethnology. Anthropology. Shopkeepers' types. Types of shops. Marketing to the Colombian style.

DIRECCIÓN PARA RECIBIR CORRESPONDENCIA: Correo electrónico: dparamo@uninorte.edu.co

\footnotetext{
* PhD en Ciencias Económicas y Sociales-Gestión de Empresas-Marketing, Université de Genéve-Suiza. Master of Management, Tulane Unversity, USA. Master en International Management, Université Catholique de Louvain, Bélgica. Especialista en Comercio Exterior, IMCEMéxico. Profesional en Mercadeo, UNEVMAC-México. Docente-investigador Escuela de Negocios, Universidad del Norte-Colombia.
}

Fecha de recibido: 4 de junio de 2012 Fecha de aceptación: 1 de agosto de 2012. 
s innegable la importancia que se le ha venido dando a la tienda de barrio, sobre todo desde que por cuenta de los procesos de apertura económica y social experimentados por la economía colombiana, algunos pensadores le auguraron su total aunque paulatina desaparición. Estos esfuerzos que han sido de carácter gubernamental y académico han permitido una más precisa comprensión de su verdadera naturaleza. De esta manera, se ha logrado tener mayor claridad sobre las razones por las cuales la tienda de barrio sigue estando vigente; no obstante, las agresivas estrategias comerciales y financieras que las grandes cadenas de la distribución al detal han implementado en busca de granjearse el favor de sus consumidores.

Algunos investigadores (Ramírez y Pachón, 2004; Páramo, 2005, 2009; Acevedo y Páramo, 2005; Acevedo et al, 2008) han descubierto que si bien es cierto las tiendas cumplen una función de carácter comercial, son los lazos sociales que crean y conservan con la comunidad en la que están instaladas los que les han permitido mantenerse (Páramo, 2009). Es su inserción en la vecindad en la que operan diariamente lo que ha hecho que todas ellas hagan parte de la existencia cotidiana de la vida del barrio.

Al ser un espacio de reforzamiento cultural del consumidor, la tienda se ha transformado en un lugar de encuentro donde no solo se realizan transacciones comerciales, sino donde se desarrollan interacciones sociales entre tenderos, amigos, vecinos, familiares. Así, los lazos sociales que se han tejido a través de estos estrechos vínculos creados a lo largo de la historia, han hecho de la tienda de barrio un punto de reunión, así sea temporal, en el que se comparten los problemas familiares, las preocupaciones individuales y los asuntos colectivos de la vecindad.

Esta misma relevancia de las tiendas de barrio y su rol en la existencia cotidiana de la comunidad (Triana, 1989), ha impuesto la necesidad de conocer e interpretar la multiplicad de relaciones que el tendero, -generalmente su propietario- establece de manera permanente con quienes se relaciona a diario. De esta manera, en busca de descubrir las teorías administrativas que de forma implícita el tendero aplica tanto en el diseño de los espacios comerciales y sociales de su tienda, como en la interacción que sostiene en su acostumbrado transcurrir, ha sido necesario desplegar plausibles esfuerzos de investigación.

Este reto que casi tímidamente se ha dirigido a descubrir las características de una administración autóctona -original- que se corresponda con las condiciones propias del entorno nacional, empieza a arrojar sus primeros resultados. Para lograrlo, ha sido vital sumergirse dentro de la realidad cotidiana de estos pequeños negocios que apenas dos décadas atrás se les auguraba su virtual desaparición (Pinilla y González, 2004).
Producto de la rigurosidad propia de los métodos etnográficos para recopilar la información, de las bondades de la etnología para comparar los diferentes matices de la compleja realidad colombiana, y de las ventajas que produce la interpretación antropológica, los primeros resultados muestran un carácter humanista de la administración de las tiendas de barrio que a algunos puede sorprender.

Las relaciones que el tendero sostiene con sus proveedores, con sus consumidores y con sus empleados, son una evidente manifestación de su sello personal, de su propia concepción de tejer vínculos sociales más que comerciales o laborales. Todo indica que son los lazos sociales los que más lo impulsan a desarrollar su actividad comercial (Páramo, 2009). Es decir, a diferencia de lo que algunos autores plantean (Rémy y Koppel 2002), los tenderos no utilizan sus relaciones sociales para cubrir sus intenciones comerciales. Por el contrario, las actividades desarrolladas en su condición de último eslabón de la cadena de distribución, le sirven al tendero para insertarse en la comunidad, hacer parte de ella, vivir en ella y contribuir al mejoramiento de sus condiciones de vida. De esta manera, la tienda de barrio, es una especie de auto-extensión (Páramo, 2009) del tendero y en esa medida su historia, su tradición, su cultura, emergen como los factores que le imprimen ese humanismo que algunos no han querido aceptar.

\section{ASPECTOS METODOLÓGICOS}

Toda la investigación se ha apoyado en los planteamientos básicos de la Grounded Theory, GT (Glaser y Strauss, 1967). Inspirados por los trabajos de Bergadaà (2006, 2008), Bergadaà et al, (2004) Bergadaà et Amraoui (2006) y Bergadaà et Del Bucchia (2007), se buscó a través de la interacción constante entre investigados, investigadores, expertos, y disertaciones teóricas, comprender la complejidad de la realidad social en la que se ha convertido la tienda y su papel reforzador de la cotidianidad de sus consumidores, como una institución social (Páramo, 2009).

La tienda de barrio fue el "territorio a explorar» (Guillemette, 2006). Como eje central de la vida de la comunidad ésta se convirtió en el punto de partida de la investigación, dado su carácter de lugar de encuentro de la vecindad y transformándose en el «texto a leer, a releer», como un referente a mirar, como punto de reflexión y análisis. Bajo esta perspectiva naturalista el desarrollo de esta investigación se hizo de acuerdo con la tradición propia de las investigaciones cualitativas. Durante todo el tiempo, -trabajo de campo, validación, análisis, categorización- esta investigación siguió fielmente la perspectiva estructurada propuesta por Miles and Huberman (2003).

A través de todo el proceso de recopilación y análisis de la información fue posible ir creando una cadena de evidencias (Hunter et al, 2002), que a su vez sirvieron de sustento empírico para la comprensión del papel 
jugado por el tendero y su tienda. De igual manera, el proceso de construcción e interpretación de las categorías encontradas se ajustó en todo momento a los requisitos de rigor planteados por Kerlinger (1985): exhaustividad, exclusión mutua y, único principio clasificatorio.

\section{Recolección de información}

Como fuente primaria básica, fueron consultados, observados y analizados 36 tenderos en tres ciudades colombianas (Manizales, Neiva y Barranquilla) y abordados a través de entrevistas semi-estructuradas. Estas entrevistas fueron sistematizadas y analizadas en matrices que sirvieron a los investigadores para identificar las primeras categorías orientadoras de la comprensión del fenómeno estudiado. La escogencia de los tenderos entrevistados se realizó en forma progresiva a partir de los resultados que se fueron obteniendo y que permitieron ir generando los conceptos preliminares, que a su vez sirvieron para la definición de las categorías descriptivas base de las categorías de mayor orden, factores claves para la estructuración de la teoría emergente (Goulding, 1998). El número de personas entrevistadas fue derivándose del proceso de comprensión a partir del «muestreo teórico» entendido como: «el proceso de recolección de datos para generar la teoría mediante la cual el analista conjuntamente recoge, codifica y analiza los datos y decide cuáles datos reunir después y dónde encontrarlos, a fin de desarrollar la teoría como surge. Este proceso de recolección de datos es «controlado» según la teoría emergente» (Glaser, 1978).

\section{Análisis de datos}

El marco general de esta investigación estuvo dado por la Grounded Theory (Teoría Fundada) con sus estrictas rigurosidades en la recopilción y validación de los hallazgos. Se desarrolló un procedimiento incremental que se desenvolvió en forma de espiral entre las características de la realidad social y las distintas corrientes teóricas acumuladas en relación con la fenomenología de hechos similares. Siguiendo un proceso cíclico a través de interacciones circulares, se fue acumulando la comprensión de las complejas relaciones establecidas dentro y alrededor de la tienda de barrio (Páramo, 2009). De las observaciones preliminares se pasó a la formulación de referentes teóricos a través del método de comparación constante entre datos recopilados en el terreno, análisis de contenido, reflexión intelectual de los investigadores, teorías emergentes y teorías similares establecidas. A través de distintos procesos de codificación, se fue incrementando el conocimiento y la comprensión de la realidad social en estudio hasta lograr los niveles de saturación teórica que hicieron «detener» el proceso. Mediante intensos ejercicios de modificación, precisión, y elaboración de conceptos, validados tanto desde la teoría como desde la perspectiva de otros actores del proceso, se logró ajustar la teoría emergida a los datos encontrados. El «ajuste emergente» (emergent-fit; Guillemette, 2006) final se alcanzó después de haber hallado similitudes, diferencias y contrastes entre las distintas categorías -empíricas y teóricas- detectadas. Los «ciclos de análisis» desarrollados a lo largo de toda la investigación comenzaron con la recopilación de unos datos preliminares estableciéndose los primeros códigos «in vivo» (Guillemette, 2006), que después de los primeros análisis de contenido fueron transformados en "códigos conceptuales» que sirvieron de base a su vez para regresar al "territorio en exploración» -tienda- para ir ratificando, rechazando, o ajustando lo hallado. Todos los análisis fueron hechos a partir de los datos obtenidos de la trascripción literal de las entrevistas, de los diarios de campo, de las fotos, de los videos obtenidos, de las conclusiones extraídas de las reuniones del equipo de investigación, de las conversaciones con expertos, de la revisión documental y de la reflexión intelectual de los investigadores (Strauss y Corbin, 1990). Este proceso fue retroalimentado con más información en algunos casos proveniente de los tenderos ya entrevistados y en otros casos, con más entrevistados escogidos mediante muestreos teóricos y nuevas observaciones-participantes y no participantesde situaciones que enriquecieron el proceso. Así de forma reiterada y sucesiva hasta alcanzar «códigos emergentes» que le fueran dando forma a las «teorías emergentes» con las cuales dar cuenta del fenómeno estudiado. Durante todo este ejercicio de análisis teorizante se buscó «leer» la realidad a partir de la convergencia entre observaciones, reflexión, datos del terreno, análisis de contenido, revisión teórica, formulación de aproximaciones teóricas; siempre respetando la rigurosidad y la honestidad intelectual implicada en estos procesos de lecturas subjetivas de complejas realidades poco o nada estudiadas.

\section{Análisis teorizante}

Toda la investigación fue desarrollada bajo el principio de la interacción circular entre la recopilación y el análisis de los datos, alternando e interactuando los procesos de recolección con los diferentes episodios de análisis de los datos (Guillemette, 2006). Estas operaciones fueron hechas de manera "conjunta» de principio a fin; una especie de «desarrollo en paralelo» (Holloway y Wheeler, 2002), en una simultaneidad de ocurrencia (Norton, 1999), una interacción continua (Morse y Richards, 2002). La formulación de la teoría fue hecha teniendo en cuenta que la teoría es «derivada de datos recopilados de manera sistemática y analizados por medio de un proceso de investigación» (Corbin y Strauss, 1990). Se hizo a través del proceso incremental de conocimientos obtenidos tanto de la recopilación y análisis de los datos obtenidos en el terreno, como de la comparación constante de éstos con la teoría existente de situaciones similares.

\section{Validación}

Los diferentes análisis de contenido llevados a cabo fueron validados de manera rigurosa a través de la contrastación, confrontación y triangulación de fuentes, métodos, investigadores y teorías (Denzin, 1989). De acuerdo con Lincoln et Guba (1985) se utilizaron 4 criterios decisivos que evitaran los sesgos tanto en la recolección de los datos, como en su análisis. 
A) La «credibilidad» fue asegurada a través de la elaboración de retratos entendidos como «síntesis escrita de los aspectos más relevantes aportados por el entrevistado que lo distinguen particularmente de los demás» (Bergadaà et Amraoui, 2006) los cuales fueron presentados y aprobados por todos y cada uno de los entrevistados en el terreno. Esta fue una validación del tipo «member check». La «confiabilidad» fue obtenida a través de la petición que se le hizo no solo a los miembros del equipo de investigación en las múltiples reuniones que se tuvieron para analizar los avances, sino a varios expertos quienes financian y promueven varios programas de apoyo a los tenderos. La «confirmación», se fue obteniendo con miembros de la comunidad consultados sobre las conclusiones obtenidas después de cada ciclo de análisis realizado -datos, análisis, contrastación teórica-. La "generalización», se obtuvo a través de las diferentes categorías encontradas.

\section{Categorización}

La categorización fue entendida como el proceso de clasificación o etiquetado de unidades de información (Spiggle, 1994) implicando, en esencia, una codificación de la cual Strauss (1987) y Strauss y Corbin (1990) han distinguido diferentes tipos y la han descrito como cierto procedimiento operativo utilizado para generar ricas categorías teóricas que les permiten a los investigadores cualitativos ir más allá de la identificación de los temas y los constructos no claramente relacionados entre sí. Para realizar esta caracterización se estructuraron matrices de análisis -preguntas orientadoras generales y preguntas específicas-, en las que se ubicaron las expresiones más dicientes como respuesta a las preguntas específicamente planteadas. Seguidamente, se realizó una evaluación detallada de las matrices con el fin de identificar la aparición de las primeras categorías analíticas (Sppigle, 1994).

Durante el desarrollo de esta etapa de análisis, la perspectiva individual empezó a desaparecer, sirviendo de base real para el surgimiento de las diferentes categorías sociales que sin poderse generalizar y extender estadísticamente a toda la población, sí han proporcionado los elementos de juicio suficientes para reconocer los diferentes rastros teóricos encontrados. Generalización categórica (Yin, 1994), que por su rigurosidad empírica se convierte en una guía para la acción de posteriores esfuerzos de investigación interesados en el conocimiento de la realidad regional de la distribución al detal en el marco de sus propias limitaciones y fortalezas.

\section{PRINCIPALES HALLAZGOS}

El tendero ha heredado sus condiciones de estratega al natural de sus ancestros, en forma de oficio que se transmite de generación en generación. Estas habilidades estratégicas se manifiestan en las relaciones que sostiene con compradores, proveedores y familiares-empleados; en la construcción de estas relaciones, ha tenido una significativa relevancia la cultura -valores, creencias, actitudes, costumbres-, desde donde ha podido detectarse una categorización de los tenderos en la que se expresan la esencia de lo que hacen.

Considerando que la tienda es una prolongación de la personalidad de su propietario (Páramo y Ramírez, 2007), la estrategia que el tendero desarrolla es captada por sus consumidores desde perspectivas diferentes. Esta percepción que hace ver a la tienda colombiana como un espacio de reforzamiento cultural del consumidor (Páramo, 2009), ha permitido descubrir una tipología de tiendas en la cual se nota la cualidad de estratega al natural que caracteriza al tendero tradicional.

\section{Razones para ejercer el oficio de tendero}

Ser tendero ha sido históricamente una actividad comercial que se ha transmitido de generación en generación, encontrándose varias razones que han llevado a los tenderos a ejercerla. Pese a que la razón que parece más obvia para que alguien haya decidido ejercer esta actividad ha sido la de generar su propio empleo, existen otros motivos de tipo cultural que afianzan la tienda en la estructura del canal tradicional de distribución.

Una de las razones más sólidas está asociada a la tradición de comerciante que algunos han heredado de sus ancestros, esta ha sido transmitida por la familia, generalmente por los padres quienes habiendo ejercido diferentes actividades comerciales han inspirado a sus hijos para que se inicien como tenderos.

El origen del tendero quien generalmente proviene de zonas rurales o semi-rurales explica la forma en que este oficio se ha transformado en una especie de proceso de desplazamiento del campo a la ciudad y ello influye de manera notoria en las relaciones que se establecen. Para quien abre una tienda el negocio le es familiar, lo aprende rápido y lo explota adecuadamente.

Para otros tenderos, la tienda ha sido un pretexto para ser ellos mismos, para hacer lo que les gusta, para hablar y escuchar, para dar consejos y hasta para servir de confidentes y trascender su rol comercial.

La vocación de servicio también ha estado presente. Entendida ésta como "una inclinación, afición, propensión para ayudar, servir, atender y orientar» (Viloria y Briceño, 2005), la vocación de servicio se expresa en la inclinación del tendero por ayudar, colaborar y 'hacer el favor' a los miembros de su vecindad.

Unido a esta vocación de servicio, está el espíritu emprendedor que caracteriza al tendero y que lo ha llevado a tomar la decisión de iniciar su propio negocio ya sea como respuesta a su tradición comercial o como necesidad de sobrevivencia con un pequeño capital y un bajo nivel de escolaridad. De esta manera, ha podido iniciar su propio negocio y en un 'rebusque' permanente 
ha 'sacado a su familia adelante' y ha estructurado de forma autónoma su propio capital.

Por otro lado, la necesidad de ser independiente hace parte de la forma de vida del tendero como una expresión natural de su autonomía y su rechazo a las formas de subordinación en las relaciones laborales ordinarias de carácter formal.

Dado el dinamismo propio de la tienda como canal tradicional de distribución, reflejado en parte en la alta rotación de capital, en la cercanía con sus compradores, en el crédito y, en las relaciones de conveniencia e inmediatez, se han podido concretar los sueños de muchos tenderos emprendedores. Éstos han iniciado su actividad sin muchos recursos pero que con su perseverancia y autocontrol han logrado constituirse en pequeños empresarios, indispensables en las relaciones de proximidad entre los miembros de su comunidad.

Por otra parte existe una clara diferencia en el papel de la mujer y el hombre en el ejercicio de la actividad como tenderos; a la mujer, la tienda le permite jugar el doble rol de trabajadora y ama de casa, para ello cuenta con elementos facilitadores con los cuales controla y administra en forma simultánea su vivienda y su negocio. Se destaca entre ellos la 'reja' (estructura metálica utilizada para controlar el libre acceso al interior de la tienda) que a pesar de su connotación de encierro y aislamiento, no es percibida por los consumidores como una barrera en la relación, sino como un elemento de protección que permite afianzar las relaciones de complicidad y colaboración entre el tendero y sus compradores.

Como una forma de aprovechar el espacio de la vivienda y buscando reducir costos de mantenimiento, el tendero manizaleño prefiere ubicar la tienda dentro de su propia casa.

\section{Relación tendero-compradores}

Es notable la particular complejidad inmersa en las relaciones que de manera cotidiana se construyen y se reconstruyen entre el tendero y su comprador, sea éste ocasional o permanente. Estas interacciones son una evidente manifestación del conjunto de redes sociales que se tejen en el seno de una vecindad anclada en la tradición y la costumbre comercial del barrio, en términos no solo de la distancia física existente entre los miembros de la misma comunidad, sino y sobre todo por la cercanía social y cultural que los lleva a compartir sus propias realidades.

Es a partir de estas circunstancias como puede comprenderse la naturaleza social de las relaciones que diariamente se crean y se reconstruyen, reforzando los patrones de comportamiento que cada día se repiten en una suerte de espiral de acercamientos cada vez más estrechos. Son estas condiciones las que le dan sentido al carácter de conveniencia, amabilidad, camaradería, complicidad y colaboración que se ha establecido, defendido, practicado y estimulado entre los tenderos y sus compradores de forma rutinaria y permanente, en la concreción de un estilo que por lo familiar acerca a unos y a otros mucho más de lo imaginado.

El hecho de que esta ancestral práctica socio-cultural se mantenga en los distintos estratos socioeconómicos -aunque con diferentes grados de intensidad-, refleja, necesariamente, una profunda y no fácilmente destructible estabilidad a lo largo del tiempo que muy seguramente no se romperá con los ímpetus modernistas que rondan el mercado nacional de ventas al detal.

La conveniencia, concebida como el grado de correlación y conformidad entre dos partes distintas lograda a través del ajuste y el convenio de acuerdos entre sí -así éstos sean tácitos-, justifica la existencia de tantas tiendas en el entorno inmediato del comprador que las visita de manera asidua, no importando ni el tamaño de sus instalaciones, ni su diseño, ni la distribución de sus espacios. La reciprocidad implícita en la relación entre el tendero y su comprador, se va construyendo y afianzando en el tiempo, a través de tácticas culturales manejadas sutilmente por ambas partes.

Unida a esta relación de conveniencia está la inmediatez, entendida como la prolongación de las funciones en el tiempo, que obedece a una lógica interna regida por la ley del rendimiento y de la eficacia. El tendero le ofrece a su comprador la posibilidad de adquirir en forma inmediata los productos que requiere de manera urgente y le permite alcanzar funcionalidad a través de la velocidad y el oportuno abastecimiento que lo lleva a iniciar o continuar con otras actividades mientras que logra el control de su tiempo.

Estas relaciones contribuyen de forma decidida a conformar un círculo de próxima e inmediata vecindad, en la que el tendero se ha transformado en un punto de referencia de la vida del barrio o de la comunidad. Es así como emerge la familiaridad, como una expresión de la naturalidad y la sencillez en el trato, propias de la amistad o del parentesco (RAE, 2007) que se reflejan en la relación entre el tendero y su comprador.

Estas relaciones de familiaridad repercuten de forma clara en la frecuencia con la que se acude a la tienda y el tendero lo manifiesta en forma de complicidad y colaboración, a través de la cual se comparte parte de su vida, se apoya, se facilita, se presta, se fía, se es solidario con las condiciones de sus compradores.

La amabilidad también hace parte fundamental de la relación que establece el tendero con sus compradores manifestada en complacencia, agrado y delicadeza en el trato con los demás (RAE. 2007). El tendero concreta esta relación en sus expresiones de formalidad y cordialidad con las cuales afianza en forma permanente sus lazos, reforzandoel trato personalizado que busca el consumidor. La confianza, expresada como subproducto de la participación en la red social a la que se pertenece 
y que se manifiesta como un «acto de fe» en quien no se conoce y de quien no se tiene información, también se concreta en la relación entre el tendero y su comprador. Esta confianza que se ve reflejada en beneficios y creencias que influyen en la decisión de confiar (Herreros, 2004), es sin duda, uno de los pilares de la relación del tendero con su comprador. Gracias a este contacto cotidiano se puede percibir cierto grado de regularidad y predictibilidad de las acciones emprendidas por unos y otros, reforzando los elevados grados de confianza mutua existente entre tenderos y consumidores.

Sobre esta confianza edificada ya sea a lo largo de los años de mutua relación, o por la experiencia acumulada por parte del tendero con la que puede detectar la esencia comercial de sus clientes, se han desarrollado prácticas comerciales que a su vez solidifican aún más dicha relación. Estas prácticas que se manifiestan, por ejemplo, en proporcionar referencias de un vecino o en flexibilizar los plazos de pago, estrechan esta y consolidan el tejido social.

Como ha de deducirse, estas relaciones entre tenderos y sus compradores han superado el carácter económico al que siempre se le ha querido asociar, dadas las dificultades que en este orden de la vida nacional se han experimentado recientemente. Por el contrario, la cercanía entre unos y otros que desemboca en una especie de mutua interdependencia presagia una relación duradera, más allá de lo estrictamente económico. Al ser la tienda una suerte de centro sociocultural donde los amigos y vecinos se encuentran no sólo para compartir instantes de aprovisionamiento, sino para departir y hablar de la cotidianidad que los invade, refuerza la idea de insustituible vecindad que subyace en sus históricas relaciones.

\section{Relación tendero-proveedores}

Dada la importancia que la tienda de barrio ha adquirido en su función comercial básica de servir de puente entre fabricantes o proveedores y compradores, las relaciones que se han tejido en la cotidiana interacción que mantienen unos y otros, también obedecen a una larga tradición que se hace evidente cada día.

No obstante, la multiplicidad de contactos con proveedores que se tienen a lo largo de la existencia de una tienda de barrio, es innegable la singular importancia que la cultura tiene en todos ellos. Se impone la costumbre de mantener relaciones cordiales y cercanas aunque, por supuesto, existen tenderos que por sus propias condiciones particulares son percibidos de forma diferente.

Esta amable y familiar relación también es percibida por parte de los proveedores como positiva, dado que siempre se busca afianzar la lógica confianza comercial que debe existir entre ellos. Aunque no se perciben insalvables dificultades, a veces aparece la indiferencia de ciertos tenderos, pero no como expresión de un lacónico desinterés, sino más bien como una estrategia comercial de obtener mejores términos de intercambio. El tendero va conociendo más al proveedor a través de cada visita que recibe, estableciéndose vínculos comerciales y sociales más estrechos. A medida que se va afianzando la mutua confianza se van manifestando relaciones que superan lo estrictamente comercial. Esta relación se transforma en amistad, cordialidad, diversión, seriedad, carisma, respeto. Toda una amalgama de expresiones de los lazos que se entrecruzan a veces de manera intermitente pero casi siempre de forma permanente.

Apesar de que el proveedor busca establecer relaciones de carácter estrictamente comercial con su cliente, la actitud asumida por el tendero, sobre todo el ubicado en los estratos bajos de la población, lleva esta relación al plano social y cultural, buscando crear una mayor cercanía que se traduzca en beneficios para él y para la comunidad. Al lograr obtener mejores condiciones comerciales, producto de la proximidad social que busca mantener con los proveedores, le es posible, a su turno, brindarle a sus vecinos mayores posibilidades en términos de precios, plazos, créditos, entre otros.

De esta manera la relación entre tenderos y proveedores está marcada por la confianza, la conveniencia, y la cercanía. La confianza permite que el tendero no sólo adquiera crédito -aunque poco le gusta- en algunos artículos de menor rotación, sino que obtiene seguridad de la calidad de los productos que está expendiendo.

La conveniencia lo induce no sólo a interactuar con el proveedor que mejor lo favorezca, sino que también le sirve para escoger su forma de aprovisionamiento. Algunos tenderos prefieren desplazarse a las plazas de mercado, a los almacenes de víveres y abarrotes, a las instalaciones de los mayoristas o incluso, a la respectiva planta de producción; otros deciden por comodidad, esperar a ser visitados por representantes de las empresas productoras o de las organizaciones encargadas del canal de tiendas.

La cercanía que se teje entre tenderos y proveedores facilita los procesos de intercambio comercial, esta cercanía contribuye, a su vez, a profundizar las relaciones entre unos y otros, sobre todo cuando provienen de una misma región del país. Se logra, incluso, al hacer parte de la misma red social, compartir tradiciones, costumbres, patrones de vida. Esta situación que se presenta con frecuencia en la costa norte colombiana en la que la mayoría de los tenderos son originarios del interior del país, se manifiesta a través de la conformación del padrinazgo (Páramo, Contreras, Arenas, 2010).

\section{Relación tendero-empleados y familiares}

Por ser la tienda de barrio un negocio esencialmente familiar, debe ser dimensionada como una organización en la que participan varios miembros de una misma familia en la que se mantienen relaciones de subordinación. Siendo la tienda un negocio familiar, es loable aceptar que en su interior se reproduce, casi 
siempre, la estructura del grupo familiar con todas las complejidades que ello genera (Páramo, García, Arias, 2007). Por un lado, todos dependen del mismo ingreso que es administrado por el jefe del hogar -hombre o mujer-y por el otro, porque las decisiones son tomadas por él mismo, pero no en su condición de propietario y administrador del negocio, sino cumpliendo su rol de cabeza de familia. Esto se traduce en inequidades laborales por cuanto casi nunca se paga un salario a sus «trabajadores» sino que se les garantiza su manutención de acuerdo con la fase del ciclo de vida en la que se encuentre cada uno de ellos (Londoño y Navas, 2005).

La colaboración es la forma predominante de la relación entre el tendero y sus familiares. Esta colaboración se refiere a la realización conjunta de un trabajo o una tarea, o a la contribución al logro de algún fin. En las actividades diarias del tendero se involucran los miembros de la familia, cuyo objetivo primordial es preservar un negocio que sienten como propio, debido también al carácter informal del mismo, la participación es espontánea y natural: colaboran hijos, hermanos, tíos de forma habitual o esporádica.

La manifestación de acompañamiento y ayuda permanente por parte de los miembros de la familia, la manifiestan los tenderos como un aporte valioso en la administración de este tradicional negocio familiar. Por ser la base del sustento de todo el grupo familiar la colaboración, se convierte en una especie de retribución de lo que se recibe para la manutención de cada uno de sus integrantes.

En su actividad cotidiana la tienda tradicional colombiana también genera empleos indirectos a través de la prestación del «servicio a domicilio» que le permite mantener las relaciones de proximidad con sus compradores. Cuando las circunstancias lo permiten, el tendero contrata trabajadores directos que le permiten aligerar las altas exigencias de tiempo y dedicación propias de la tienda debido al amplio horario de atención que ofrece a sus compradores.

Este proceso de contratación de personas ajenas al grupo familiar se ha convertido en una auténtica dificultad para el tendero. Los elevados grados de confianza que se deben tener en las personas que van a vivir en la intimidad familiar del tendero, obstaculiza la vinculación laboral con excepción de los dependientes patrocinados por los padrinos costeños, quienes en el futuro se transformarán en tenderos (Páramo, Contreras, Arenas, 2010).

\section{La cultura en las relaciones tendero-compradores- empleados}

Una detallada revisión de las diferentes manifestaciones de las relaciones que sostiene el tendero con compradores, proveedores y familiares y empleados, muestra el innegable papel que juega la cultura en su creación, aceptación y consolidación. Asumiendo que la cultura es un marco de acción bajo el cual sus miembros actúan en función de los cánones establecidos, se destacan los valores, las creencias, las actitudes, las costumbres y la tradición como las dimensiones culturales de mayor impacto en la estructuración y naturaleza de tales relaciones.

Los valores que por su raíz histórica se han instalado en las esferas dominantes de una sociedad y por lo mismo han adquirido la connotación de verdades absolutas e irrefutables sirviendo como patrones de referencia para aceptar o rechazar comportamientos, han tenido una gran incidencia en la vida del tendero. Entre los valores presentes en la interacción del tendero con el comprador, el proveedor, o el empleado, se destacan unos de marcada influencia y connotación social orientados por el entorno como la tolerancia, el respeto, la confianza y la familiaridad.

- La tolerancia se manifiesta no solo en el grado de aceptaciónque tiene el tendero de los otros agentes sociales con los que se relaciona, sino en la paciencia que evidencia para atender de la mejor manera posible a sus compradores, para esperar la visita de su proveedor y para transmitirle las enseñanzas básicas a sus empleados o familiares.

- El respeto se traduce en la forma en como el tendero conduce sus interacciones, siempre en función del valor que para él tienen sus congéneres. No obstante que el tendero bromea con las diferentes personas con las que se relaciona, incluso utilizando apodos para referirse a algunas de ellas, existe respeto en cada interacción que tiene. A pesar que algunos de ellos coquetean con las mujeres que los visitan, en general, no se evidencian manifestaciones de irrespeto que los haga merecedores de una condena social. Existe informalidad pero no irrespeto.

- La confianza se evidencia no solo al creerle a la gente lo que le dicen, sino para relacionarse con los demás. Al practicar este valor cultural el tendero se hace acreedor de confianza por parte de los demás. El proveedor le fía sin exigirle documentos especiales, sus familiares confían en sus recomendaciones, pero sobre todo los compradores le depositan toda su confianza al dejarle a su cuidado las llaves de sus residencias, algunos objetos e incluso, a sus hijos.

- La familiaridad es un valor cultural de enorme trascendencia en la vida cotidiana del tendero de barrio. A través de su práctica se expresa el sensible grado de cercanía que guarda con todos con quienes se relaciona. El tendero de barrio ha dejado de ser un comerciante quien expende productos que la comunidad demanda, ahora es un vecino que contribuye a la solución de los problemas de su vecindario. Es una fuente de información, apoya la conformación de equipos deportivos, es miembro de la junta de acción comunal de su barrio, patrocina eventos sociales colectivos. Es un familiar para quien las dificultades de su barrio hacen parte del inventario de sus preocupaciones. 
- Existen otros valores influenciados por el grado de apropiación y respeto que cada individuo tiene por lo predominante en una cultura dada, orientados por uno mismo. (Hawkins, 1994). Entre éstos se destacan la responsabilidad, la honestidad y la pertenencia, manifestados fuertemente en el nivel socioeconómico alto coincidiendo con el carácter de tendero empresario.

- El tendero es responsable, honesto y tiene un alto grado de pertenencia a la comunidad en la que vive. Su responsabilidad se refleja en todo lo que hace de forma honesta por el bien propio, el de su familia y el del vecindario. Su grado de pertenencia se evidencia aún más cuando debe fungir como representante ante alguna institución pública o privada en la que debe llevar la vocería de su comunidad.

Las creencias que son concebidas como afirmaciones «de hecho» manifestadas en afirmaciones verbales 0 mentales del tipo «yo creo» (Acevedo, 2005), también muestran una alta incidencia en la vida cotidiana de los tenderos.

- La creencia dominante en el tendero tiene que ver con el tiempo de dedicación a todas las actividades inherentes a la tienda, que le exigen una permanente predisposición a dedicar todo su trabajo y muchas veces el de su familia a la atención de sus clientes. Esto ha hecho que el mismo tendero crea que las tiendas son negocios «esclavizantes» y de continuo contacto con el cliente para poderlo conservar y con ello aplicar uno de los postulados claves del marketing (Páramo 2004).

- De igual manera el tendero cree que el éxito de su negocio radica en la manera como atiende a sus compradores. Esta atención no es descrita por ellos como el tradicional servicio al cliente (Lovelock. 1986), sino como uno de sus particulares diferenciales en los que se conjugan de forma armónica la amabilidad, la simpatía y la cordialidad.

- A pesar del gran esfuerzo cotidiano que realiza el tendero por mantener su tienda de acuerdo con las exigencias y las demandas de sus compradores, se manifiesta una ancestral creencia muy propia de las regiones más tradicionales del país de atribuir el éxito a la suerte o a la acción divina.

- El conocimiento que tiene el tendero de su comprador, de su proveedor y de sus empleados en cuanto a su capacidad de pago, su confiabilidad como deudor, su puntual cumplimiento en la entrega de mercancías, y la confianza que le debe brindar a sus dependientes lo lleva a creer que él tiene la malicia suficiente para definir quién merece su confianza en esta relación. Aceptando que la actitud «es un estado mental o neural dispuesto, organizado por medio de la experiencia, que ejerce una influencia rectora o dinámica en la respuesta del individuo a todos los objetos y situaciones con los que se relaciona» (Allport, 1935; citado en Worchel y Cooper), puede verse cómo éstas favorecen la interacción entre el tendero y sus congéneres.
Algunas de estas actitudes son:

- De descalificación y rechazo frente al cliente incumplido.

De autocontrol con los gastos familiares que afectan el negocio.

-De escucha y receptora de la comunicación de la comunidad.

-De propiciar espacios de diálogo.

- De proporcionar ambientes de camaradería.

-De halagar a sus compradores.

Por otro lado, es en las costumbres donde más se nota el arraigo que tienen los tenderos en el alma colectiva de la comunidad. Es aquí donde surgen las prácticas más ancestrales que denotan la inseparabilidad de las tiendas del seno de la vida de la sociedad (Páramo, García, Arias, 2006). Es tal el peso de las costumbres que es a partir de su cotidiana repetición como se ha contribuido a la creación de un lenguaje propio con el cual se identifican ciertas prácticas cotidianas asociadas a las permanentes relaciones del tendero.

\section{Estas costumbres se pueden sintetizar así:}

-Convertir la tienda en un «bar» para complacer a sus clientes.

- Tener en la tienda algo para la «buena suerte».

- Hacer productos caseros para vender en la tienda. - Involucrar a la familia en la atención del negocio.

- Dar el dulce o la «ñapa» a los niños.

- Ofrecer productos típicos de la cultura agroalimentaria de la región.

- Ofrecer algo para propiciar el espacio para conversar. - Ofrecer una atención a sus clientes ofreciendo una «ronda» (expresión utilizada para invitar a tomar licor a un grupo de personas que se encuentra departiendo en algún ligar), entre otras.

En el marco de todo aquello que una generación hereda de las anteriores y que por considerarlo valioso lo toma para sí, las tiendas han jugado un papel relevante en la vida de la comunidad (Acevedo, Ramírez, Páramo, 2008). Ello explica la existencia de estos centros socioculturales que cumplen una función comercial por todos los rincones de la ciudad.

Es tal la larga tradición -del latín traditio- de contacto permanente con las tiendas insertadas en el tejido social de toda la comunidad que éstas aparecen por doquier y se pueden encontrar varias no solo en un mismo barrio sino sobre todo en una misma cuadra. Todas ellas compartiendo el vecindario, participando en la vida social de la comunidad, construyendo sociedad (Páramo, 2009). La tienda no solo hace parte del circuito comercial de distribución al detal de ciudades y poblaciones, sino que ha logrado meterse en el inconsciente colectivo de la sociedad entera. Su omnipresencia se siente en la dinámica vida del vecindario, sirviendo como un reforzador cultural del consumidor y asegurando su continuidad (Páramo, García, Arias, 2006). 


\section{Tipología de tenderos}

Los tenderos son individuos que de manera decidida participan en las decisiones que le conciernen a su comunidad. De esta forma, toman parte activa en la elección del presidente de la república, del gobernador, del alcalde y de toda suerte de comicios electorales que le conciernen a la ciudadanía en general. Sus preocupaciones también están relacionadas con la seguridad del barrio, la situación económica del país, los problemas de violencia, el desempleo, la corrupción y de una manera muy significativa los problemas personales de sus vecinos y de convivencia (Páramo, García y Arias, 2007).

El tendero líder actúa de manera correcta. Siendo capaz de influir en forma positiva en las decisiones de la comunidad, es proactivo. Brinda a todas las personas con las que se relaciona un excelente trato y procura siempre ofrecer productos que cumplan con los mínimos estándares de calidad a precios asequibles. En general, pertenece a agremiaciones locales como las juntas de acción comunal, demostrando su capacidad de impulsar procesos sociales de interés colectivo. Está en capacidad de contribuir a la elección de sus mandatarios ya que goza de un buen apoyo de la comunidad, porque además de ser quien les provee de alimentos, es el amigo que los escucha y de una u otra manera soluciona sus problemas tanto personales como económicos (Páramo, García y Arias, 2007).

Al estudiar, analizar y sobre todo al interpretar la realidad social tejida alrededor de la interacción entre el tendero y sus compradores, sus proveedores y sus empleados, se detectó una tipología que por estar estrechamente conectada con las circunstancias propias de la cotidianidad, representándola, puede servir como guía estratégica para quienes pretendan seguir en este sector de la economía colombiana.

Esta emergente tipología ha sido construida alrededor de dos factores determinantes; por un lado, se consideraron los valores agregados de acuerdo con determinadas consideraciones culturales que han motivado al tendero a ejercer su actividad y que están presentes su cotidianidad y por el otro, se ha recurrido al modelo de Schein (1985) a través de la interacción establecida entre comportamientos-en este caso asociados a la costumbre- valores y creencias $y$, el mundo subyacente. En todas y cada una de las categorías se evidencia no sólo el carácter humanista del tendero, sino su destacada proyección social hacia la comunidad de la que hace parte y por la que desarrolla actividades que superan aquellas asociadas a la función puramente comercial.

\section{Tendero incondicional}

Es una persona a quien le gusta participar en la solución de los problemas de los otros, lo que le permite sentirse útil, imprescindible y necesario. Sus principales roles son los de confidente y colaborador. El reconocimiento y la participación son sus principales valores agregados. Los valores más representativos que guían su accionar son: la familiaridad, la empatía, el compromiso, la colaboración. La creencia más ampliamente reconocida en él es verlo como un proveedor de soluciones más que de un expendedor de productos. Este tendero acostumbra a propiciar espacios para escuchar y charlar con otras personas.

\section{Tendero cómplice}

Su característica principal es la de ser amiguero y muy sociable. Dada su permanente actitud de colaboradory conversador, interactúa con sus clientes ayudándoles a resolver sus problemas más sentidos sobre todo los que se relacionan con sus necesidades más urgentes. Es tal su compromiso con su vecindario que es capaz de ofrecerle a sus clientes algunos de los productos perecederos que él necesita para su consumo personal y el de su familia; además les proporciona los espacios sociales requeridos para que su clientela interactúe en un ambiente de esparcimiento y camaradería. La cortesía, la simpatía, la colaboración y el apoyo como consideraciones culturales, fortalecen su sociabilidad como valor agregado, ratificado por su costumbre de interactuar con la gente.

\section{Tendero sobreviviente}

Se caracteriza por su permanente capacidad de lucha y su indomable espíritu de superación que le permite enfrentarse a los retos que cotidianamente se le presentan. Predominan en él la cooperación, la empatía, la responsabilidad y la independencia como valores culturales. Cree que el éxito de su negocio está en su deseo de superación y autorrealización, siendo éste el principal valor agregado que recibe de la tienda.

\section{Tendero hogareño}

Es una persona extrovertida, apasionada por lo que hace, que sostiene estrechas relaciones interpersonales con sus clientes y proveedores. Este tendero es considerado un excelente consejero, un amigo: es paciente con los niños, se da a la gente, tiene un elevado espíritu de entrega hacia los demás que lo hace merecedor del aprecio del barrio, lo buscan, incluso para el desarrollo de actividades completamente ajenas a su labor comercial como aplicar inyecciones o prestar primeros auxilios. La responsabilidad y la familiaridad son sus valores culturales más arraigados y la independencia el valor agregado que recibe de su trabajo como tendero. Generalmente este rol es asumido por mujeres quienes además expresan su más profundo sentido maternal. En este caso la mujer tendera ejerce un doble rol, como trabajadora y como responsable del hogar.

\section{Tendero paisano}

De origen campesino, ha heredado su vocación de comerciante de sus ancestros, posee un bajo nivel de escolaridad. Desde muy joven instala su negocio para colaborar con los gastos de la familia; el gusto por negociar y manejar dinero son sus principales características. Es un tendero consagrado, formal, amable, atento y le gusta tener su tienda bien organizada y limpia. Sus habilidades comerciales le proporcionan 
independencia y autosuficiencia como sus principales valores agregados aunque le parece esclavizante, le gusta lo que hace y siente como propia la tienda, vive de ella. El respeto y la honestidad son los valores culturales que guían su conducta en las relaciones que establece con compradores, proveedores, o empleados.

\section{Tendero patrón}

Es un tendero cuya característica principal es la de tener empleados, esto le exige tener capacidad de mando, de organización y de control sobre sus finanzas y sobre todos los procesos relacionados con la administración de la tienda En lo personal, es un individuo que realiza sus propias inversiones, maneja cuentas y créditos bancarios en el sector financiero, aunque sus proveedores le ofrecen crédito rara vez lo utiliza. Tiene empleados a sueldo con sus respectivas prestaciones sociales, anualmente toma vacaciones con su familia. Generalmente la tienda no está en su lugar de residencia. La autosuficiencia y la autonomía son los valores culturales que rigen su actividad, cree que el éxito de su negocio depende de la suerte y de su carisma, aunque reconoce que su dedicación se convierte en esclavitud. Acostumbra a interactuar con la gente.

\section{Tendero departidor}

Es el tendero que comparte con sus clientes el consumo de licor en su establecimiento. Acostumbra a convertir la tienda en un 'bar' en el que se departe, se escucha música, se conversa, se bromea, se divierte. Para atender a sus clientes les brinda «rondas» de licor como una invitación personal que se convierte en un estímulo para que se siga ingiriendo alcohol. Le gusta tener en la tienda objetos que según sus creencias son de buena suerte. Su actividad la ha aprendido por tradición familiar y demuestra ser comerciante por vocación. Sus valores agregados son la autonomía, la autosuficiencia y la comodidad de poder ubicar la tienda dentro de su vivienda o cerca de ella.

\section{Tendero rebuscador}

Es el individuo que encuentra en la tienda la posibilidad de solucionar en forma ocasional, ingeniosa y rápida su situación personal. Ve en su montaje una manera de optimizar sus escasos recursos en búsqueda de obtener ingresos estables que le aseguren su supervivencia y la de su familia. De ahí que la mayoría ubica la tienda dentro de su vivienda como una manera de alivianar la carga que implica el sostenimiento familiar. En su proyecto de vida no considera quedarse cumpliendo el rol de tendero, lo que lo lleva a estar buscando siempre mejores opciones laborales. Para él, la tienda es una forma de rebusque.

\section{Tipología de tiendas desde la perspectiva del consumidor}

A partir de analizar los procesos de inserción de la tienda en el seno de la vecindad en la que se halla ubicada, se han detectado 13 tipos de tiendas que por la homogeneidad entre varias de ellas han sido agrupadas en tres grandes categorías: a) Por su apariencia física (pequeña, ordenada y aseada), b) por familiaridad (familiar, popular, placentera, servicial, sacadora de apuros) por intermediación (surtida, todera, mercadera, miniaturizadora, básica).

\section{Tiendas por su apariencia}

Una parte de los consumidores de tienda ve en ellas un espacio físico cuyas características de tamaño, distribución, orden y limpieza son determinantes para mantener y alimentar sus relaciones permanentes. Los conceptos de pequeñez, orden y aseo se encuentran en la mente de cada consumidor. Ello explica la admiración que despierta la capacidad de los tenderos de distribuir el reducido espacio disponible para lograr una exhibición armónica de los productos que expende y gusto que siente el consumidor al visitar su tienda preferida. Pensar, entonces en la tienda es traer a la mente las características más relevantes desde lo físico, pequeña, ordenada, aseada.

Esta apariencia física como rasgo típico que prevalece en la mente de algunos consumidores de tienda y las comodidades que de allí se pueden derivar, solo se puede explicar por el significado cultural de estos conceptos en la tradición colombiana. Se está tan acostumbrado a las tiendas que es difícil imaginarlas de grandes tamaños y con una gran cantidad de empleados tratando de prestar un adecuado servicio. El criterio de un «lugar de comodidad» (Bergadaà et Del Bucchia, 2009), solo puede considerarse desde la perspectiva del consumidor de este tipo de negocios y no desde la concepción de comodidad desarrollada en las grandes superficies de distribución. En la tienda se aprovechan todos los espacios para repartir la reducida superficie disponible. En la mayoría de ellas prevalece el aseo y el orden de todos los elementos -mesas, asientos, mostradores, exhibidores- que confluyen para que en su interior se desarrollen las relaciones entre los consumidores y sus tenderos.

Al ser percibida la tienda como pequeña, poseedora de una serie de características con las que se le asocia en su cotidiano discurrir, se está haciendo referencia a cómo en el interior de unos pocos metros cuadrados el tendero exhibe sustanciales cantidades de productos en diferentes presentaciones, sobre todo las más reducidas en tamaño (Botero et Jaraba, 2005).

La tienda es visualizada como una reducida área física, donde el consumidor es atendido con esmero y dedicación y en la cual tras de un mostrador se encuentra una o varias personas -generalmente de la misma familia- dispuestas a ayudarlo en sus más originales necesidades, no importando si en algunas de estos locales, por motivos de inseguridad social, tengan que empotrar rejas que los separan. En su reducido espacio interior se impone el orden y el aseo, y donde lo poquito se organiza para surtir en cantidades pequeñas las demandas de sus consumidores.

No obstante, el reducido espacio en el que se exhiben y se expenden los productos, la tienda es evocada 
como ordenada, en la que cualquier persona puede encontrar fácilmente lo que pueda necesitar. La observación detenida de los estantes en los que se acomodan y muestran los productos a los visitantes de la tienda es suficiente para corroborar la gran capacidad que tiene el tendero para colocar todo, en forma ordenada, en los estrechos espacios disponibles. De igual manera la distribución de los muebles y los enseres disponibles son puestos de forma tal que cada espacio es aprovechado al máximo.

La tienda también es evocada como aseada donde impera la limpieza y los buenos aromas. La tienda ordenada produce ganas de entrar a ella a disfrutarla como un lugar donde el consumidor se siente cómodo. En este tipo de tiendas es difícil que ronden animales e insectos aunque se expendan productos perecederos. El aseo se transforma casi en una posesión del tendero y eso al ser percibido por sus consumidores, se convierte en un diferenciador social de gran importancia.

\section{Tiendas por familiaridad}

La tienda también es vista como algo muy cerca de sus propios mundos en una suerte de «medio cómplice» (Bergadaà et Del Bucchia, 2009). Un espacio en el cual los consumidores se sienten como en su propio hogar, incluso con cierto grado de intimidad. Todo ello se traduce en una cercanía social de gran significado no solo en la cotidianidad de sus vidas sino cuando una emergencia aparece. El tendero está dispuesto a ayudar, a apoyar cualquier causa que pueda demandar su participación, incluso la financiación de eventos de gran importancia para la comunidad en su conjunto.

La profundidad de sus contactos es de tal envergadura que para muchos la tienda es el club social al que tienen acceso gratuito y donde no se les exigen requisitos especiales. Es suficiente con hacer parte de la comunidad y tener cierta confianza con el tendero para divertirse, ingerir bebidas alcohólicas, practicar juegos de mesa -dominó, cartas-, escuchar la música preferida, bailar y obtener crédito sin llenar formatos especiales ni presentar avales de garantía de pago (Acevedo et al, 2008).

Esta familiaridad con la que se hacen evidentes los fuertes lazos (Granovetter, 1973) tejidos en el interior de la comunidad alrededor de la omnipresencia de los tenderos y la función social que cumplen, explica los elevados grados de confianza mutua construidos en la vida diaria. Se fía sin referencias crediticias de instituciones especializadas en una modalidad conocida como «credi-marlboro» dado que las cuentas son registradas al reverso de un pedazo de cartón del empaque de la famosa marca de cigarrillos. Solo se necesita el instinto del tendero para confiar en su «vecino», en su amigo.

De esta manera se encuentran tiendas familiares, populares, placenteras, serviciales, y sacadoras de apuros que contribuyen al reforzamiento cultural del consumidor. En su interior se tejen redes de apoyo, de solidaridad, de confianza fortaleciendo las relaciones de proximidad (Guedon, 2005), que coadyuvan a su propia auto-reproducción.

La tienda familiar es vista como un espacio comercial donde pueden acudir todos los miembros de la familia. Se exhiben múltiples tipos y variedades de productos, incluso de diferentes marcas dentro de una misma categoría. El surtido es amplio, expendiéndose productos tanto de la canasta familiar básica -sobre todo perecederos-como de otras naturalezas: de aseo, de higiene personal.

Pensar en la tienda popular significa no solamente que ésta se encuentra en cualquier barrio, sino que hace parte integral de la cultura del vecindario. Es asociarla con el local de «al lado» ratificando el concepto de vecindad, puesto que solo basta con traspasar la puerta del domicilio del consumidor para encontrarse en la cercanía de la tienda, tan solo a unos metros del lugar de residencia. Esta connotación de reducida distancia física denota la existencia de un ambiente de gran cercanía, propio de las vecindades más conocidas. Se encuentra por todas partes, es popular. Lo popular de esta tienda es asociado con «lo corriente», como una forma abierta de reiterar una vez más la importancia que tiene ella en la vida de los consumidores de cada ciudad. La tienda hace parte del inventario de su propio mundo en el cual el diseño, el esquema y la forma de trabajar de ella se han entronizado en la cotidianidad de su propia existencia.

Hacer referencia a «lo popular» cuando se piensa en una tienda significa que ellas se encuentran por doquier, en cada esquina, en cada cuadra, en cada manzana, en cada barrio, en cada comuna. Lo extraño sería no volver a ver estos locales porque para todos los consumidores su presencia es un hecho, es una parte inherente al concepto de vida en sociedad. Las tiendas se han incrustado en la conciencia, en el pensamiento y en el rutinario actuar de propios y extraños.

En contraste con los aspectos logísticos y comerciales asociados, la tienda es vislumbrada como placentera, un "sitio social», un punto de encuentro de amigos, familiares y conocidos. Un lugar donde se comparte la vida, la existenciahumana de sus miembros, al que se acude más por razones de tipo social y cultural que por las propiamente económicas. Admitir que la tienda es sinónimo de "disfrute y gozo», es reconocerle una función distinta a la de proveedora de alimentos y productos esenciales; es ratificar el carácter social que estos espacios tienen como reforzadores culturales del comportamiento del consumidor (Páramo, García, Arias, 2007). Convenir el carácter departidor y bohemio de estos sitios es retomar su historia iniciada en las tradicionales chicherías que en la Bogotá de la Conquista y la Colonia se asentaron en el primer piso de las edificaciones de la época (Cordovez, 1978). Se ve la tienda como el lugar donde es posible departir, al calor de un trago de aguardiente o de una cerveza, con algunos amigos pero sin ser vistos por los familiares. 
Algunas de estas tiendas han adecuado un espacio para estos menesteres en lo que popularmente es reconocido como la «trastienda», oculto, íntimo, cómplice.

En la tienda servicial se resalta la característica principal que distingue a los tenderos de los empleados de las grandes superficies, su vocación de servicio. El tendero y todos sus trabajadores, generalmente familiares, han mostrado tener una clara inclinación a servirle a su comunidad en todo lo que esté a su alcance. Desde fiarles a sus consumidores sin ningún respaldo financiero hasta prestarles dinero cuando sus condiciones económicas se deterioran o cuando una calamidad familiar o una emergencia se imponen. Estas situaciones, sobre todo las que se presentan de forma inesperada, son posibles de ser resueltas en parte también porque el tendero vive en su negocio. La tienda es parte de la casa.

Aceptar que la tienda es "parte de la casa» implica, por otro lado, admitir que el espacio destinado a la concreción de las transacciones comerciales es una extensión física de la habitación, aunque en términos reales haya sido una reducción del espacio destinado a la familia. Generalmente, la tienda ha sido ubicada en lo que en otro fuera la sala de la casa o una parte del garaje. Esta particular mezcla entre lo familiar y lo comercial ha contribuido de manera sensible, no sólo a mejorar los niveles de servicio, sino a estrechar los lazos entre tenderos y consumidores, dado que la atención al cliente puede hacerse prácticamente a cualquier hora del día o de la noche. Basta con llamar a la ventana o a la puerta del tendero para que éste interrumpa su sueño y satisfaga los requerimientos de su «vecino».

Teniendo en cuenta que las tiendas están por todas partes, se encuentran bien surtidas y se puede adquirir todo lo que se necesite, es imaginada como sacadora de apuros, como un local donde todos los problemas son resueltos. De igual manera, el tendero ayuda a resolver problemas inauditos asociados a la cotidianidad de sus consumidores. Esto es posible, no sólo porque el tendero mantiene la actitud positiva de ayudar siempre a sus vecinos, sino porque además él habita en el mismo espacio físico donde tiene instalada su tienda, a veces en el segundo piso de la vivienda o en la parte trasera del negocio.

Tiendas por intermediación

Asignándoseles el rol que desde la perspectiva comercial las tiendas han cumplido al servir de vínculo logístico entre fabricantes, mayoristas o minoristas por un lado y los consumidores por el otro, la tienda es visualizada como intermediaria. Las representaciones mentales que se tienen de este tipo de tiendas han permitido verlas como el último extremo -ventas al detal- de la cadena de distribución que parte de la empresa fabricante y llega al consumidor final (Pinilla y González, 2004).

A pesar de que estas características propias de la función de intermediación se cumplen a diario en la tienda, los consumidores la siguen viendo desde sus propios patrones. El imaginario colectivo en el que se anclan las tiendas mercaderas, surtidas, toderas, miniaturizadoras y básicas es tan propio de las manifestaciones culturales colombianas que clasificaciones como las de lugar-hábito (Bergadaà et Del Bucchia, 2009) que explican el hábito que adquieren las personas para visitar una tienda, no alcanzan a explicar la complejidad de los fenómenos vividos en el interior de la tienda de barrio.

Aceptar que la tienda es sinónimo de una superficie mercadera es verla como aquel espacio comercial y social en el cual los consumidores se aprovisionan diariamente. Es considerarla como el sitio para «hacer el mercado» que requiere una familia. Es allí donde diaria, semanal o quincenalmente se hacen todas las compras que se demanden, no importando el tipo de producto. De esta manera, la tienda es el proveedor de productos perecederos y no perecederos y es la que evita que los habitantes de la zona tengan que desplazarse a otros lugares de la ciudad en busca de víveres y abarrotes. Ello por supuesto le da más fuerza a la idea de "vecindario» que convierte a la tienda en un especial factor social de aglutinamiento y cohesión. Al ser un «mercadero» se establecen conexiones mentales entre la tienda y «la atención» que refleja un claro convencimiento de parte de los tenderos de la naturaleza humana en términos de que todos buscamos el buen trato, el respeto, y relaciones agradables.

Al practicarse el buen trato y la buena atención, el consumidor adquiere la costumbre de comprar cada cierto tiempo en su tienda preferida. La tienda en los estratos más bajos se encuentra inserta en la cotidianidad de la existencia colectiva y su rol es más relevante para el desenvolvimiento de la vida social en comunidad, convirtiéndose en un particular referente para entender la vida urbana y en sociedad (Ramírez y Pachón, 2004) en función de las relaciones establecidas entre los agentes comerciales que toman parte en el intercambio del que se ocupa el marketing y que Spillman (1999) ha visualizado desde sus más claras connotaciones culturales.

Para los consumidores de los estratos altos esta función de aprovisionamiento no se presenta como una actividad diaria en la que adquieren todos los productos necesarios. La tienda cumple un rol complementario a las compras que semanal, mensual o quincenalmente se hacen (Acevedo, Páramo, Ramírez, 2008). En la tienda solo se compra lo que se agota en la despensa y casi siempre por vía telefónica.

Al pensar en la tienda como surtida se está ratificando la función más comercial que tradicionalmente se le ha asignado en los diferentes estratos de la población; es decir cumpliendo su papel de aprovisionadora circunstancial o permanente de aquellos productos que se agotan en la despensa familiar (Pinilla y González, 2004). Con esta visión se está reiterando,el rol que como canal de distribución tradicional ha cumplido la tienda sirviendo, a su vez, de puente entre proveedores 
-mayoristas, fabricantes, plazas de mercado, distribuidores- y consumidor final.

La tienda todera es un espacio donde los consumidores pueden encontrar «de todo» así ésta ocupe un local pequeño y estrecho. Pensar en la tienda como una todera es relacionarla con "las cositas» que los consumidores demandan. Es reforzar la imagen que allí es posible encontrar «de todo», principalmente todo lo pequeño, lo mínimo. Es una ratificación más de la repetida construcción mental que hacen algunos consumidores en relación con el reducido mundo que parece encerrar este centro de encuentro entre los miembros de una misma comunidad.

En la tienda miniaturizadora, las evidencias demuestran que en ella es posible surtirse de las cosas menos imaginadas con la particularidad que muchas han sido sometidas a un práctico proceso de miniaturización de sus presentaciones. En estos locales convergen diversas categorías de productos desde los perecederos que requieren cadenas de frío hasta los enlatados que pueden ser exhibidos en estantes bajo temperatura ambiente. Es tal la decisión de disponer de un surtido lo más completo posible que cuando algún producto no se encuentra el tendero se encarga de adquirirlo y ponerlo a disposición del consumidor.

Esta práctica que ha sido tradicional entre los tenderos quienes siempre han miniaturizado las presentaciones desde cuando por tradición adquirían productos a granel -arroz, azúcar, sal, por ejemplo- para después venderlos por libras, kilos, medias libras o cuartos de libra, se ha incrementado de manera notable en los últimos tiempos por la decisión de los fabricantes de hacerlo en otras categorías de productos. Los productores, después de comprender la realidad del mercado al detal, han decidido reducir el tamaño de la presentación de sus productos líderes permitiendo que los consumidores tengan la posibilidad de adquirir shampoo, jabón, pañales, pañuelos desechables, café, panela, entre otros, por unidades o por fracciones de unidad. Casi en cualquier tienda colombiana es posible adquirir productos por gramos, onzas, medias libras, tres cuartos de libra, por centímetros, por cucharadas, cuartos de litro, medio litro.

Asegurar que existe una tienda básica, es reconocer que ella se ha convertido en un factor esencial en la vida de los miembros de la comunidad en la que se ha asentado. Dado que allí puede encontrarse solo lo vital, lo fundamental para la supervivencia, todo lo superfluo debe buscarse en sitios distintos. Ello significa que en tanto el tendero siga cumpliendo este anhelo, podrá perdurar mucho más de lo que algunos puedan imaginar. Es muy probable que estos consumidores soporten la presión modernista que trae la tecnología de las grandes superficies que se ha venido imponiendo en Colombia desde principios de la década de los años 90 del siglo pasado.

\section{CONCLUSIONES}

Es innegable el papel cumplido por los tenderos de barrio en el inevitable enlace que cada día mantienen entre la vida de la comunidad y su labor cotidiana. EI desenvolvimiento de sus actividades denota no solo el aspecto humano de su gestión, sino la trascendencia que ellas han ganado al contribuir al mejoramiento de las condiciones de vida del vecindario donde ellas se ubican. Las tiendas al ser una prolongación de la personalidad del tendero tienden también a humanizarse, dado que en su interior no solo se transan bienes y servicios, sino que se refuerza la identidad de todos quienes se encuentran en su interior.

Esta realidad refuerza los hallazgos hasta ahora alcanzados en el sentido de ver a la tienda de barrio como un espacio en el sentido de ser un lugar (Bergadaà, 2008), fuertemente simbolizado en el cual se puede leer en parte o en su totalidad la identidad de quienes interactúan en ella y con ella de forma permanente (Augé, 2007). En su diario acontecer se tejen relaciones de tal intensidad que éstas han contribuido a mantener y prolongar en el tiempo la historia que tenderos, compradores, proveedores y empleados han compartido desde siglos atrás. Es un espacio de reforzamiento cultural del consumidor (Páramo, 2009).

La familiaridad detectada en el estudio desarrollado sobre los tenderos (Páramo, García, Arias, 2007) tiene una gran significación no solo en relación con la función comercial que ellos cumplen, sino y sobre todo, respecto al conocimiento y acercamiento personal que existe entre tenderos y consumidores. La confianza mutua devenida en amistad e incluso, en intimidad y complicidad, ha servido para ratificar los auténticos lazos creados en la cotidianidad de sus existencias. El valor simbólico que tiene la tienda para el desenvolvimiento de la vida de la comunidad en la cual se halla inserta, es el que no ha permitido que la sobremodernidad se haya impuesto «a las conciencias individuales» mediante "experiencias de soledad ligadas a los no lugares» (Augé, 1993).

En este sentido, el tendero y sus decisiones cotidianas contribuye de manera decidida a que la tienda sea «un lugar, no un no-lugar» (Páramo, 2009). El tendero estimula la permanencia de los consumidores, las interacciones entre ellos, la vida en comunidad. Su diario accionar refuerza la idea de que la tienda es un espacio donde se estructuran las relaciones en un tiempo y un lugar concretos (Giddens, 1984) y donde se encarnan las experiencias y las aspiraciones individuales y colectivas de quienes crecen a su alrededor y en contacto con ella, siendo un espacio vivido (Gómez, 2001), el de las experiencias humanas, cotidianas (Cassirer, 1989). El mundo que el tendero ayuda a construir y se desenvuelve en el interior de la tienda se aleja de los "sobremodernos» espacios de consumo -super e hipermercados- como los que comenzaron a construirse en Colombia a partir de 
la apertura económica vivida desde 1990 y donde no se inscriben relaciones sociales duraderas. Se distancia también del mundo de las grandes cadenas hoteleras, de las superautopistas, de los aeropuertos y de las estaciones de gasolina donde los individuos se mueven sin «relacionarse, ni negociar nada» aunque «obedecen a un cierto número de pautas y códigos que les permiten guiarse, cada uno por su lado» (Augé, 2007).

La visión del tendero ayuda a que en la tienda se inicien, desarrollen, conserven y reproduzcan relaciones sociales que vienen de antaño como una clara expresión de proximidad en todas sus dimensiones (Grossetti, 1998; Le Boulch, 2001). Coadyuvan a reforzar la tradición, los valores culturales, las creencias y las costumbres más prominentes aprendidas desde los primeros años de vida y ello, seguramente garantizará su supervivencia en el largo plazo. Los fuertes lazos (Granovetter, 1973) tejidos entre tenderos y consumidores han personalizado las relaciones que aunque en un comienzo han sido construidas alrededor de la tarea comercial de la tienda al servir de puente entre distribuidores minoristas y consumidores, las ha trascendido en una suerte de relaciones de proximidad identitaria (Páramo, 2009; Grossetti, 1998) creando redes sociales que se encargan de reproducirse a sí mismas.

Estos fuertes lazos sociales han sido en parte los encargados de reproducir la cultura y sus manifestaciones más conocidas a través no solo de las prácticas comerciales que en la tienda se desarrollan, sino mediante los comportamientos, las creencias y los valores que emergen como expresión del mundo subyacente (Schein, 1985) anidado en lo más profundo de la conciencia de tenderos y consumidores colombianos.

\section{REFERENCIAS}

Acevedo, Ch. (2005). Relativismo y marketing: una propuesta metodológica para el estudio del comportamiento del consumidor. Pensamiento y Gestión. No. 19. Universidad del Norte.

Acevedo, Ch., y Páramo, D. (2005). Valores, creencias y orientación temporal del consumidor de la tienda barranquillera. Cali: Ponencia ASCOLFA.

Acevedo, Ch. (2005). Creencias y valores de la tienda tradicional en Barranquilla. Universidad del Norte. Maestría en Administración.

Acevedo, Ch.; Ramírez, E., y Páramo, D. (2008). ¿Por qué las tiendas de barrio en Colombia no han fracasado frente a las grandes cadenas de supermercados? Ediciones USCO Universidad Surcolombiana de Neiva.

Arnould E. J., y Thompson C. J. (2005). Consumer culture theory (CCT): Twenty Years of Research. Journal of Consumer Research, 31, March, 868-882.

Augé, M. (1993). Los no-lugares. Espacios del anonimato. Una antropología de la sobremodernidad. España: Gedisa.

Augé, M. (2007). Sobremodernidad. Del mundo de hoy al mundo de mañana. Contrastes. Revista cultural, 47, 101-107.

Bergadaà, M. (2006). Une stratégie de recherche constructiviste appliquée aux services culturels : l'exemple du Musée Olympique, de son concept et de ses profils types de visiteurs. Recherche et Application en Marketing, 21(3), 24.

Bergadaà, M. et Amraoui, (2006). La proximité au lieu de vente : comment implique-t-elle le client ? Observatoire de Vente et Stratégies du Marketing (OVSM). HEC. Université de Genève. Suisse.

Bergadaà, M., et Del Bucchia, C. (2009). La recherche de proximité par le client dans le secteur de la grande consommation alimentaire. Revue ManagementetAvenir. 21(1), 121-135.

Bergadaa, M. (2006). Une stratégie de recherche constructiviste appliquée aux services culturels : l'exemple du Musée Olympique, de son concept et de ses profils types de visiteurs. Recherche et Application en Marketing, 21(3), 24.

Bergadaa, M. (2008). L'artisanat d'un métier d'art : l'expérience de l'authenticité et sa réalisation dans les lieux de rencontre entre artisan et amateur éclairé. 23(3), 5- 25.

Bonilla, E., y Rodríguez, P. (2005). Más allá del dilema de los métodos. Bogotá: Norma.

Bromley, R. (1998). Market-place trading and the transformation of retail space in the expanding Latin American City. Urban Studies; Jul. 35. 8.

Corbin, J., \& Strauss, A. (1990). Grounded theory research: Procedures, canons, and evaluative criteria. Qualitative Sociology, 13, 3-21.

Denzin, N. (1989). Interpretive interactionism. Applied Social Research Methods Series. 16. Sage Publications.

Diccionario Manual de la Lengua Española Vox. (C) 2007, Larousse Editorial, S.L.

Farhangmehrl, M., Marques, S., Silva, J. (2000). Consumer and retailer perceptions of hypermarkets and traditional retail stores in Portugal Journal of Retailing and Consumer Services 7.

Findlay, A., Paddison, R., Dawson, J. (Eds.), (1990). Retailing environments in developing countries. London: Routledge.

García-Canclini, N. (1989). Culturas híbridas: Estrategias para entrar y salir de la modernidad. México: Grijalbo. 
Geertz, C. (1973). The interpretation of cultures. New York: Basic Books.

Giddens, A. (1984). The constitution of society. Outline of the theory of structuration. Berkeley and Los Angeles: University of California Press.

Glaser, B.G. (1978). Theoretical Sensitivity. Mill Valley, CA: Sociology Press.

Glaser, B.G., \& Strauss, A.L. (1967). The discovery of grounded theory: Strategies for Qualitative Research. Chicago, IL: Aldine.

Goldman, A. (1974). Outreach of consumers and the modernization of food retailing in developing countries. Journal of Marketing, october, 38.

Goldman, A. (1981). Transfer of a retailing technology into less developed countries: the supermarket case. Journal of Retailing, 57, 2.

Goldman, A. (1982). Adoption of supermarkets shopping. In Kaynak, E., Cavusgil, T. (1982) The evolution of food retailing systems: contrasting the experience of developed and developing Countries. Journal of the Academy of Marketing, 10, 3 .

Goldman, A., \& Hino, H. (2005). Supermarkets vs. traditional retail stores: diagnosing the barriers to supermarkets' market share growth in an ethnic minority community. Journal of Retailing and Consumer Services 12.

Goldman, A., Ramaswami, S., Krider, R. (2002). Barriers to the advancement of modern food retail formats: theory and measurement. Journal of Retailing, 78.

Gómez J.C. (2001). La experiencia cultural del espacio: el espacio vivido y el espacio abstracto. Una perspectiva ricoeureana. Investigaciones geográficas, Boletín del Instituto de Geografía, 44, 119-125.

Granovetter, Mark S. (1973). The strength of weak ties. American Journal of Sociology, 78(6), 1360-1380.

Grossetti, M. (1998). La proximité en sociologie: une réflexion à partir des systèmes locaux d'innovation. In Approches multiformes de la proximité / Paris: Hermès.

Guedon, J. (2005). Approches de la notion de proximité en sciences socials. Ecole de Management de Normandie. CR 36. Octobre.

Guillemette, François (2006). L'approche de la Grounded Theory; pour innover? Recherches qualitatives, 26(1), 32-50.

Hall, E. (1976). Beyond culture. New York: Anchor Books.

Hernández, L. (2000). Colombia Retail Food Sector 2000. USDA Foreign Agricultural Service Global Agricultural Information Network Report \# CO0033. Washington, DC: USDA.

Herreros, F. (2004). Universidad Nacional Autónoma de México-Instituto de Investigaciones Sociales. Revista Mexicana de Sociología. 66(4), Octubre-Diciembre 2004. México D.F. 605-626. ISSN 01882503/04/06604-01.
Holloway, I., \& Wheeler, S. (2002). Qualitative Research in Nursing (2da ed.). Oxford, UK : Blackwell.

Hunt, S. D. (1976). The nature and scope of marketing. Journal of Marketing, 40 (July), 17-28.

Hunter, A. et al (2002). Making meaning: the creative component in qualitative research. Qualitative Health Research. 12, 3.

Ibrahim, M., \& Wee, Ch. (2002). Determinants of entertaining shopping experiences and their link to consumer behaviour. Case studies of shopping centres in Singapore. Journal of Leisure Property, 2 Dec, 4.

Kaynak, E., Cavusgil, S.T. (1982). The evolution of food retailing systems. constrasting the experience of developing countries. Journal of Academy of Marketing Science, 10, 249-269.

Kerlinger, F.N. (1985). Investigación del comportamiento. Técnicas y metodología. México: Interamericana.

Kumar, N. (997). The revolution in retailing: from market driven to market driving. Long Range Planning, 30, 6.

Lambin Ch., Hair J. y Mc Daniel C. (2002). Marketing. México. D.F: Thompson Editores, S.A.

Le Boulch, J. (2001). Approche systémique de la proximité : définition et discussion. Troisièmes Journées de la Proximité, Paris, 13-14 décembre.

Lemoine, J. (2004). Magasin d'atmosphère: quelles evolutions et quelles perspectives d'avenir. Revue Francaise du Marketing. 198, 3-5.

Levi-Strauss C. (1976). El mono desnudo. España: Siglo $\mathrm{XXI}$

Levy, S. (1978). Hunger and work in a civilized tribe or, the anthropology of market transactions. The American Behavioral Scientist. Mar/Apr. 21, 4.

Londoño, E., Navas, M. (2005). Canal tradicional en Colombia. Tiendas de barrio. En Investigación en Administración en América Latina: Evolución y resultados. Universidad Nacional de Colombia. Sede Manizales.

Lovelock, C. H. (1986). Marketing of services. In V.P. Buell ( $2^{\text {da }}$ ed), Handbook of Marketing. New York: McGraw-Hill.

Malinovsky, B. (1967). A diary in the strict sense of the term. New York: Harcourt.

Malinowski, B. (1975). La vida sexual de los salvajes del nordeste de la Melanesia. España: Morata.

Martínez, M. (2006). La investigación cualitativa: síntesis conceptual. Revista de Investigación en Psicología, 9(1), 123-146.

Mehrabian, A. (1972). Nonverbal communications Chicago: Aldine.

Miles, M., \& Huberman, M. (2003). Analyse des données qualitatives. Belgique: De Boeck Université Éditions. 
Morse, J.M. \& Richards, L. (2002). Readme first. Thousand Oaks, CA: Sage.

Norton, L. (1999). The philosophical bases of grounded theory and their implications for research practice. Nurse Researcher, 7(1), 31-43.

Páramo, D. (2005). Ethnomarketing, the cultural dimension of marketing. Revista Pensamiento \& Gestión, 18. División de Ciencias Administrativas. Universidad del Norte. Barranquilla.

Páramo, D. (2009). Le commerce traditionnel colombien: un espace de renforcement culturel pour les consomateurs. Thèse prèsentèeà la Facultè des Sciences Ėconomiques et Sociales de L'Universitè de Genève - Suiza.

Páramo, D., García, O. L., Arias, M. O. (2007). Consumidor de tienda Manizaleña. Una mirada cultural. Manizales: Centro Editorial Universidad de Manizales.

Páramo, D., y Ramírez, E. (2007). Gerencia Estratégica de Marketing. Un enfoque cultural. Neiva: Universidad Surcolombiana.

Páramo, D; Contreras, M; Arenas, J. (2010). El canal tradicional en Barranquilla. Evolución y prácticas comerciales. Barranquilla: ASAB.

Pestana, C., Alves (2003). Hypermarket retail store efficiency in Portugal International. Journal of Retail \& Distribution Management, 31, 11-12.

Pinilla, O.; González, G. (2004). Estudio comparativo de las características del merchandising aplicado la tienda tradicional de Barranquilla en estratos 2 y 5 . Trabajo de Grado Especialización en Gerencia de empresas comerciales. División de Ciencias Administrativas. Universidad del Norte.

Ramírez, O., y Pachón, A. (2004). Una forma para entender la ciudad. Relaciones sociales y prácticas culturales en tres escenarios de mercado. Editorial Universidad Surcolombiana.

Real Academia Española. RAE (2007) http://www.rae.es/

Reardon, T., Berdegué, J. (2003). La rápida expansión de los supermercados en América Latina: Desafíos y oportunidades para el desarrollo. RUR-03-01. Washington, D.C. Junio.

Rémy, E., Kopel, S. (2002). Social Linking and Human Resources Management in the Service Sector. The Service Industries Journal, 1(22), 35-56.

Samiee, S. (1993). Retail and channel consideration in developing countries: a review. Journal of Business Research 27, 2.

Schein, E. (1985). Organizations, culture and leadership. San Francisco: Jossey-Bass.

Spiggle, S. (1994). Analysis and interpretation of qualitative data in consumer. Journal of Consumer Research, 21, 3.

Spillman, L. (1999). Enriching exchange: cultural dimensions of markets. New York: The American Journal of Economics and Sociology.

Strauss, A., \& Corbin, J. (1990). Basics of qualitative research: Grounded theory procedures and techniques. Beverly Hills. C.A: Sage Publications, USA.

Triana, G. (1989). La cultura popular en Colombia. En Nueva Historia de Colombia. Bogotá: Planeta.

Wilcox, M., \& O'Callaghan, E. (2001). The strategic response of Dublin's traditional department stores to intensifying competition. Journal of Retailing and Consumer Services, 8.

Yin, R.K. (1994). Case Study Research - Design and Methods, Applied Social Research Methods. Series 5, $\left(2^{\text {nd }}\right.$ ed. $)$. Newbury Park, CA: Sage.

Revista que publica cuatrimestralmente la DACEA-UJAT, se encuentra dentro del LATINDEX (Catálogo de Revistas Latinoamericanas) desde el mes de diciembre del año 2000 , e indizada en CLASE (base de datos bibliográfica en Ciencias Sociales y Humanidades de la Universidad Nacional Autónoma de México) a partir del 23 de enero del 2001.

\section{http://www.dgbiblio.unam.mx}

Actualmente, nuestra publicación periódica está totalmente digitalizada y la puedes encontrar en la página WEB de la UJAT y es posible accesar a ella a través de:

\section{www.ujat.mx/publicaciones/hitos}

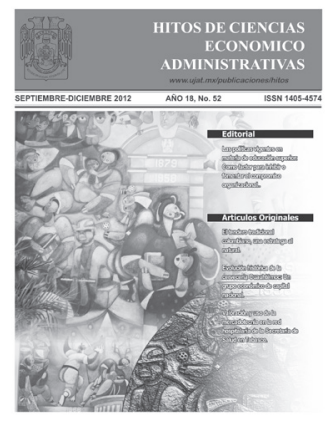

HITOS DE CIENCIAS ECONOMICO ADMINISTRATIVAS

HITOS DE CIENCIAS ECONÓMICO ADMINISTRATIVAS 